\title{
Optimization and Static Stress Analysis of Hybrid Fiber Reinforced Composite Leaf Spring
}

\author{
Luay Muhammed Ali Ismaeel \\ Machineries and Equipments Technologies Department, Najaf Technical Institute, Iraq \\ Correspondence should be addressed to Luay Muhammed Ali Ismaeel; luay.m.63@gmail.com
}

Received 7 July 2014; Revised 19 October 2014; Accepted 22 October 2014

Academic Editor: Kwangho Kim

Copyright ( 2015 Luay Muhammed Ali Ismaeel. This is an open access article distributed under the Creative Commons Attribution License, which permits unrestricted use, distribution, and reproduction in any medium, provided the original work is properly cited.

\begin{abstract}
A monofiber reinforced composite leaf spring is proposed as an alternative to the typical steel one as it is characterized by high strength-to-weight ratio. Different reinforcing schemes are suggested to fabricate the leaf spring. The composite and the typical steel leaf springs are subjected to the same working conditions. A weight saving of about more than $60 \%$ can be achieved while maintaining the strength for the structures under consideration. The objective of the present study was to replace material for leaf spring. This study suggests various materials of hybrid fiber reinforced plastics (HFRP). Also the effects of shear moduli of the fibers, matrices, and the composites on the composites performance and responses are discussed. The results and behaviors of each are compared with each other and verified by comparison with analytical solution; a good convergence is found between them. The elastic properties of the hybrid composites are calculated using rules of mixtures and Halpin-Tsi equation through the software of MATLAB v-7. The problem is also analyzed by the technique of finite element analysis (FEA) through the software of ANSYS v-14. An element modeling was done for every leaf with eight-node 3D brick element (SOLID185 3D 8-Node Structural Solid).
\end{abstract}

\section{Introduction}

Leaf springs are special kind of springs used in automobile suspension systems. The advantage of leaf spring over helical spring is that the ends of the spring may be guided along a definite path as it deflects to act as a structural member in addition to energy absorbing device [1]. In order to conserve natural resources and economize energy, weight reduction has been the main focus of automobile manufacturers in the present scenario. Weight reduction can be achieved primarily by the introduction of better material, design optimization, and better manufacturing processes [2]. The suspension leaf spring is one of the potential items for weight reduction in automobile as it accounts for ten to twenty percent of the unsprung weight. This helps in achieving the vehicle with improved riding qualities. It is well known that springs are designed to absorb and store energy and then release it. Hence, the strain energy of the material becomes a major factor in designing the springs. The relationship of the specific strain energy can be expressed as [2]

$$
U=\frac{\sigma^{2}}{2 \rho E}
$$

where $\sigma$ is the strength, $\rho$ the density, and $E$ the Young modulus of the spring material. It can be easily observed that material having lower modulus and density will have a greater specific strain energy capacity. The introduction of composite materials has made reducing the weight of the leaf spring possible without any reduction on load carrying capacity and stiffness. Since the composite materials have more elastic strain energy storage capacity and high strength-to-weight ratio as compared to those of steel, they are proposed for such a task [3]. In addition, composite and hybrid composite materials have good corrosion resistance and tailorable properties [4]. In this work, an analysis of a hybrid composite monoleaf spring is made with many different composite materials constructed from four fibers each with three composite matrices (a composite matrix is that one composed of short fibers and a certain matrix material), with various volume fractions in order to get vast range of collections of different 
hybrid composites. The design constraints are the bending and Von Mises stresses and deflections. The leaf spring should absorb vertical vibrations and impacts due to road irregularities by means of vibrations in the spring deflection so that the potential energy is stored in spring as strain energy and then released slowly [5]. Other advantages of using fiberreinforced polymers instead of steel are (a) the possibility of reducing noise, vibrations, and ride harshness due to their high damping factors; (b) the absence of corrosion problems, which means lower maintenance costs; and (c) lower tooling costs, which has favorable impact on the manufacturing costs [4]. Advanced composite materials seem ideally suited for suspension (leaf spring) applications. Their elastic properties can be adjusted to increase the strength and reduce the stresses induced during application [6]. This paper is mainly focused on the implementation of composite materials by replacing steel in conventional leaf springs of a suspension system. This is the reason why leaf springs are still used widely in a variety of automobiles to carry axial loads, lateral loads, and brake-torque in the suspension system. Therefore analysis of composite material leaf springs has become essential in showing the comparative results with conventional leaf springs.

\section{Literature Survey}

A lot of studies and researches were carried out on the applications of the composite materials in monoleaf springs. kumar and Vijayarangan [7] studied and tested monoleaf spring fabricated from a traditional E-glass/epoxy composite material for the static load conditions; fatigue life prediction was also done by these authors so as to ensure a reliable number of life cycles of that spring. Cyclic creep and cyclic deformation were also studied by Yang and Wang [8]. Fuentes et al. [9], Clarke and Borowski [10], and Mayer et al. [11] studied the premature failure in leaf springs so as to suggest remedies on application of composite leaf springs. Patunkar and Dolas discussed modelling and analysis of composite leaf spring under the static load condition by using FEA, but they did not mention much about hybrid composite materials; it is again E-glass/epoxy material adopted for their work [12]. Some of the recent works turned to discuss the geometric shape of the leaf spring made from traditional metallic alloys; Kumar and Aggarwal considered the parabolic leaf spring and studied its effect on the performance and behavior of the leaf spring used by a light commercial automotive vehicle. The researchers used a CAD modeling of parabolic leaf spring which has been done in CATIA V5 and the analysis of the model is imported and performed in ANSYS11 workbench [13]. This paper focuses on introducing hybrid fiber-reinforced composite materials of various reinforcing schemes in order to get more detailed scene about the effect of different factors on the response of and stresses induced in the leaf spring. These factors include effects of matrix material variation, fiber type variation, and fiber volume fraction. The leaf spring adopted in this paper is of elliptic geometry and only a half of it is considered here (Figure 3), due to the symmetry about the center U-bolt (Figure 4) [14]. Elliptic leaf springs are the most common types of suspension and springing used in automobiles due to their larger radius of curvature than parabolic counterparts [15].

2.1. Fabrication of Hybrid Composite Leaf Spring. The pattern is made up of wood. The pattern dimensions are calculated by the dimensions of designed leaf spring, as shown in Figure 4(a). This process requires developing a mold or a pattern as described below.

2.2. Development of Pattern. For fabrication of composite spring, the composition of fibers and matrix should be used. For this paper E-glass fiber and epoxy (as well as other types of fibers and matrices) as a composite matrix are used. The constant cross-section is selected for design due to its capability of mass production and accommodating continuous reinforcement of fibers and also it is quite suitable for hand lay-up technique. Some methods of fabrication are as follows [16]:

(1) pultrusion;

(2) resin transfer molding (RTM);

(3) vacuum assisted resin transfer molding (VARTM);

(4) hand lay-up-open molding process;

(5) compression molding;

(6) filament winding.

The leaf spring is going to be fabricated by hand layup method [16-18]. Hand lay-up method is adopted for fabrication due to its advantages over the others. Tooling cost is low, no skilled worker is required, large items can be fabricated, it is an easy method compared to others, and so forth.

Hand Lay-Up Method. See the following.

(1) Cutting of Fibers. For this project the fiber material, for example, E-glass, is taken. This fiber is available in sheet format. This fiber sheet is cut by composite scissor.

(2) Preparation of Composite Matrix (Epoxy/Short Fibers). In preparation of matrix we used two solutions named resin and hardener. After preparation of epoxy matrix, the composite matrix is fabricated constituting one type of short fibers selected in the paper. The composite matrix composed of short fibers and a polymeric matrix can be prepared after the completion of the epoxy matrix by the method of "fiberglass spray lay-up process": fiberglass spray lay-up process is very different from the hand lay-up process. The difference comes from the application of the fibre and resin material to the mold. Spray-up is an open-molding composites fabrication process where resin and reinforcements are sprayed onto a reusable mold. The resin and glass may be applied separately or simultaneously "chopped" in a combined stream from a chopper gun. Workers roll out the spray-up to compact the laminate. The part is then cured, cooled, and removed from the mold. 
2.3. Fabrication. First take the wood pattern (Figure 4(a)), on which keep plastic bagging first as per the dimensions available. On the bagging keep peel ply of the same dimension. The bagging is required to leak proof fabrication or the resin should not be in contact with the pattern. Resin is sticky in nature and hence the contact with pattern should be avoided. Peel ply is required for the finishing of the required component. Now, keep the first sheet of fiber and apply the composite matrix over the first fiber sheet. Apply composite matrix such that all air should be removed. Now, keep the second lamina over the applied matrix and again apply matrix as discussed above. Continue this process till the last fiber sheet. The produced leaf spring is as shown in Figure 4(b).

\section{Theory and Mathematical Formulation of Leaf Spring}

A spring is defined as an elastic body, whose function is to distort when loaded and to recover its original shape when the load is removed (Figure 2). Leaf springs absorb vehicle vibrations, shocks, and bump loads (induced due to road irregularities) by means of spring deflections, so that the potential energy is stored in the leaf spring and then relieved slowly [1]. Ability to store and absorb more amount of strain energy ensures the comfortable suspension system. Semielliptic leaf springs are almost universally used for suspension in light and heavy commercial vehicles. For cars also, these are widely used in rear suspension. The spring consists of a number of leaves called blades. The blades are varying in length. The blades are usually given an initial curvature or cambered so that they will tend to straighten under the load (Figure 1). The leaf spring is based upon the theory of a beam of uniform strength. The lengthiest blade has eyes on its ends. This blade is called main or master leaf; the remaining blades are called graduated leaves. All the blades are bound together by means of steel straps (Figure 4). The spring is mounted on the axle of the vehicle. The entire vehicle load rests on the leaf spring. The front end of the spring is connected to the frame with a simple pin joint, while the rear end of the spring is connected with a shackle. Shackle is the flexible link which connects leaf spring rear eye and frame. When the vehicle comes across a projection on the road surface, the wheel moves up, leading to deflection of the spring. This changes the length between the spring eyes. If both the ends are fixed, the spring will not be able to accommodate this change of length. So, to accommodate this change in length, shackle is provided at one end, which gives a flexible connection. The front eye of the leaf spring is constrained in all the directions, whereas rear eye is not constrained in $x$-direction. This rear eye is connected to the shackle. During loading the spring deflects and moves in the direction perpendicular to the load applied. When the leaf spring deflects, the upper side of each leaf tip slides or rubs against the lower side of the leaf above it. This produces some damping reducing spring vibrations, but this type of damping may change with time, so it is preferred not to be depended on. Moreover, it produces squeaking sound. Further if moisture is also present, such interleaf friction will

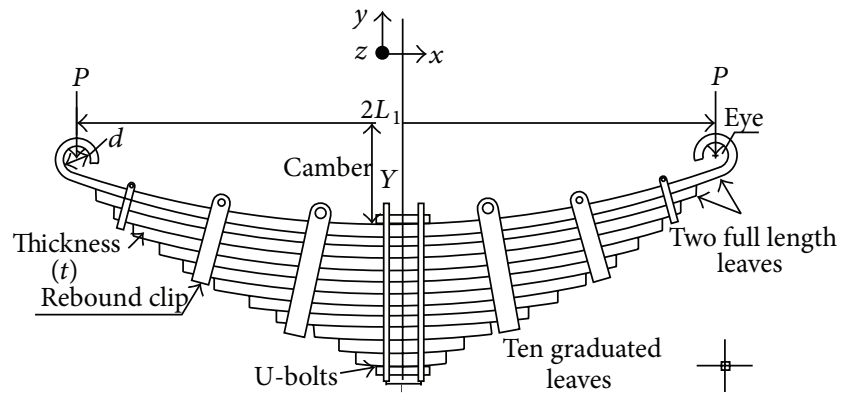

FIGURE 1: Typical leaf spring structure showing symmetry about central U-bolt.

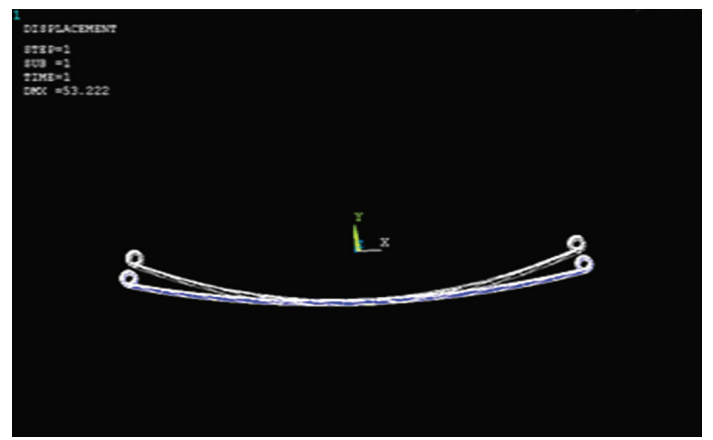

FIGURE 2: Geometry of leaf spring in ANSYS before and after deflection.

cause fretting corrosion which decreases the fatigue strength of the spring; phosphate paint may reduce this problem fairly. The elements of leaf spring are shown in Figure 1, where $t$ is the thickness of the plate, $b$ is the width of the plate, and $2 L$ is the length of plate or distance of the load $W$ from the cantilever end. A single leaf spring blade can be treated as a cantilever beam with a concentrated load at its free end $[1,4,14]$. A half of it is considered for the purpose of analysis and computation (Figures 3 through 5) $[14,19]$.

Let $t$ be thickness of plate (spring leaf), $b$ width of plate, and $L$ length of plate or distance of the load $W$ from the cantilever end.

It is known that the maximum deflection for a cantilever with concentrated load at free end is given by

$$
\delta_{\max }=\frac{W \cdot L^{3}}{3 \cdot E \cdot I}
$$

and the maximum bending stress induced in terms of modulus of elasticity and maximum deflection can be found as $[1,2,19]$

$$
\sigma_{\text {bending }}=\frac{3 \cdot E \cdot \delta_{\max } \cdot t}{2 L^{2}}
$$

where $\delta_{\max }$ is maximum deflection in (m). $W$ is applied load on the cantilever end in $(\mathrm{N}) . L$ is distance from the cantilever end to the central bolt (in meters). $E$ is modulus of elasticity $\left(\mathrm{N} / \mathrm{m}^{2}\right) . t$ is leaf spring plate thickness $(\mathrm{m})$.

For composite materials, the modulus of elasticity $(E)$ mentioned in (2) and (3) is taken as the longitudinal modulus 


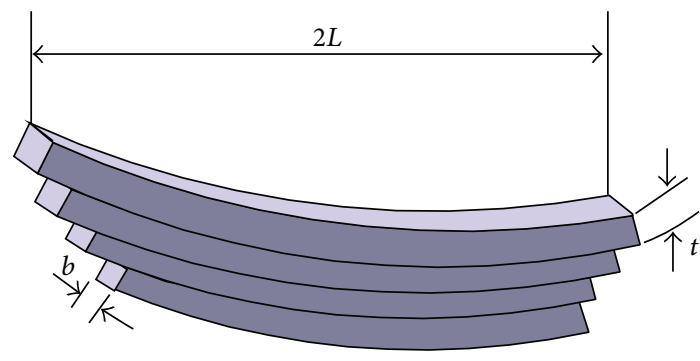

FIGURE 3: Elements of leaf spring.

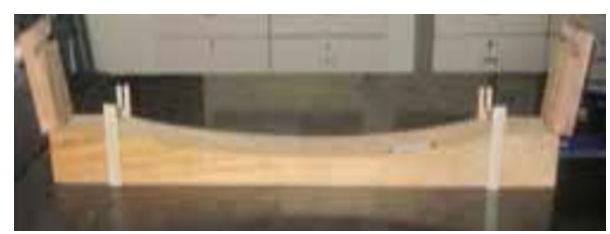

(a)

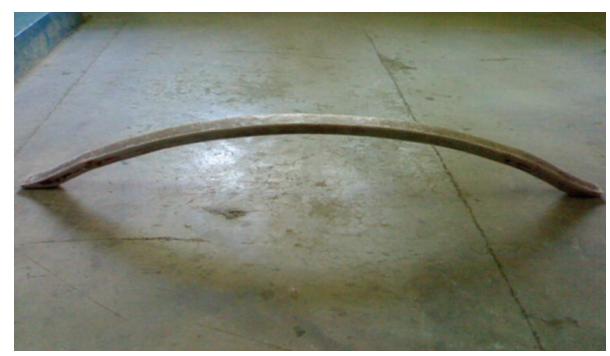

(b)

FIgUre 4: (a) Configuration of the pattern. (b) A monocomposite leaf spring.

of elasticity, which is the one being in the direction of fibers. The model of this paper is constructed such that its matrix is made up from short fibers and a pure matrix to form a composite matrix. Long fibers are then used to reinforce the composite matrix constituting a hybrid composite material. Thus (3) can be rewritten as follows to match with composite materials considerations:

$$
\begin{gathered}
\delta_{\max }=\frac{W \cdot L^{3}}{3 \cdot E_{1} \cdot I}, \\
\sigma_{x}=\frac{3 \cdot E_{1} \cdot \delta_{\max } \cdot t}{2 L^{2}} .
\end{gathered}
$$

The bending stress is in the $x$-direction because the reinforcing longitudinal fibers are laid along the longitudinal direction of spring plate. The model of interest is drawn and built in AutoCAD Mechanical v-2010 and then analyzed in ANSYS14, as shown in Figures 2 and 5, with the following dimensions which are either exactly or approximately commonly adopted for such an application [20].

(1) Plate width $=200 \mathrm{~mm}$.

(2) Plate thickness $=40 \mathrm{~mm}$.

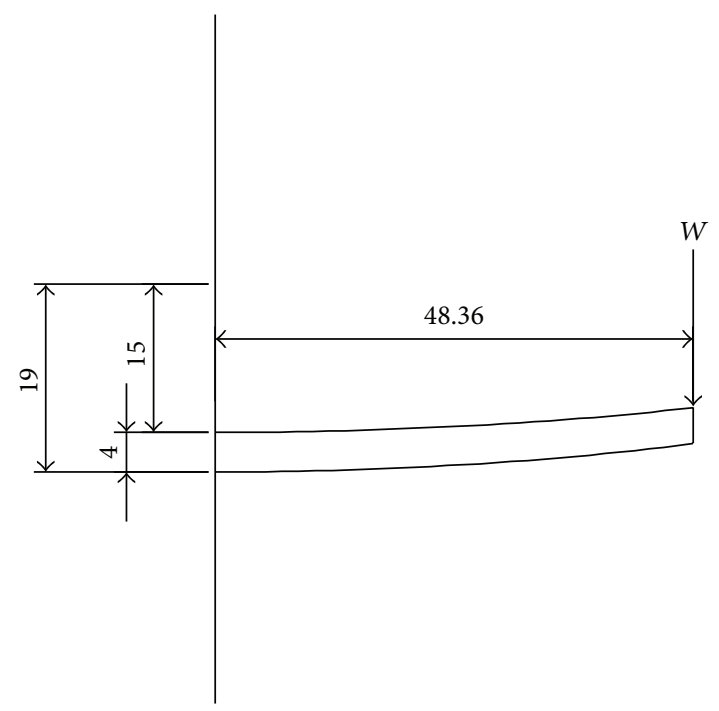

FIGURE 5: A half of an elliptic monoleaf spring.

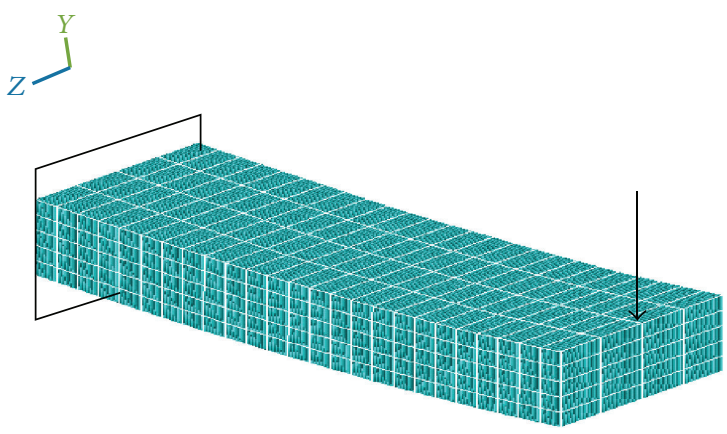

FIGURE 6: Meshing and boundary conditions of the ANSYS model.

(3) Total length of leaf spring $=0.966 \mathrm{~m}$.

(4) Camber $=150 \mathrm{~mm}$.

The applied load on the leaf spring of interest equals the automobile total weight which is about $3000 \mathrm{Kgs}$ with 5 passengers of about $100 \mathrm{Kgs}$ each; therefore

$$
\begin{aligned}
W_{\text {total }} & =3000+5 * 100 * 9.81 \\
& =34335 \mathrm{~N} \text { let it be } 35000 \mathrm{~N} .
\end{aligned}
$$

Each tire shares a load of $35000 / 4=8750$ N. Thus a load of this magnitude will be considered for the leaf spring as the applied load (Figure 5). The single leaf is first modeled in AutoCAD Mechanical 2010 as two concentric ellipses as shown in Figure 5. Afterwards, the configuration is moved to ANSYS-14 by generating key points extracted from the AutoCAD file and then mapped-meshed according to the element type of eight-node 3D brick element (SOLID-185 3D 8-Node Structural Solid). Boundary conditions are then imposed for an applied bending load at the free end of $8750 \mathrm{~N}$ with locking all degrees of freedom of the cutting plane zone at the middle of leaf spring due to its symmetry (Figures 5 and 6). 
Equations (2) and (4) will be considered for the analytical calculations of deflection and bending stresses for the purpose of results verification and comparison with numerical findings obtained from the software ANSYS.

\section{Assumptions}

The following assumptions are adopted for both of the fibers and matrix while a static bending analysis of a hybrid fiber-reinforced composite leaf spring is made assuming the following [21].

(1) The longitudinal stress in the fiber varies linearly across its width while the transverse stress is uniform across the fiber.

(2) Perfect bonding between fibers and matrix is assumed to exist.

(3) Fibers and matrix are assumed to be isotropic, homogeneous, and linearly elastic.

(4) No voids, inclusions, impurities, or manufacturing defects and deficiencies are assumed to be involved in spring material.

(5) The composite material is considered homogeneous on macroscopic level.

(6) The loads are assumed to be applied at the infinity (for the sake of the problem of contact stresses and the Saint Venant principle to be turned away).

(7) Initially stress-free

(8) The composite material is transversely isotropic [21].

(9) The short fibers are randomly and homogeneously distributed throughout matrix material constituting the composite matrix such that it exhibits isotropic behavior [22].

\section{Mathematical Formulation of Hybrid Composite Material}

5.1. Composite Lamina Composed of Composite Matrix and Reinforcement Continuous Fiber

5.1.1. Composite Matrix (Combination of Resin and Discontinuous Fiber). For unidirectional fiber-reinforced matrix shown in Figure 7, the following Halpin-Tsai relations are used to determine the elastic properties [22, 23]:

$$
\begin{aligned}
& E_{1 m}=\frac{1+2 \cdot a_{f} \cdot \eta_{l} \cdot \forall_{s f m}}{1-\eta_{l} \cdot \forall_{s f m}} \cdot E_{m}, \\
& E_{2 m}=\frac{1+2 \cdot \eta_{T} \cdot \forall_{s f m}}{1-\eta_{T} \cdot \forall_{s f m}} \cdot E_{m}, \\
& G_{12 m}=\frac{1+\eta_{G} \cdot \forall_{s f m}}{1-\eta_{G} \cdot \forall_{s f m}} \cdot G_{m}, \\
& v_{12 m}=v_{s f} \cdot \forall_{s f m}+v_{m} \cdot \forall_{m m},
\end{aligned}
$$

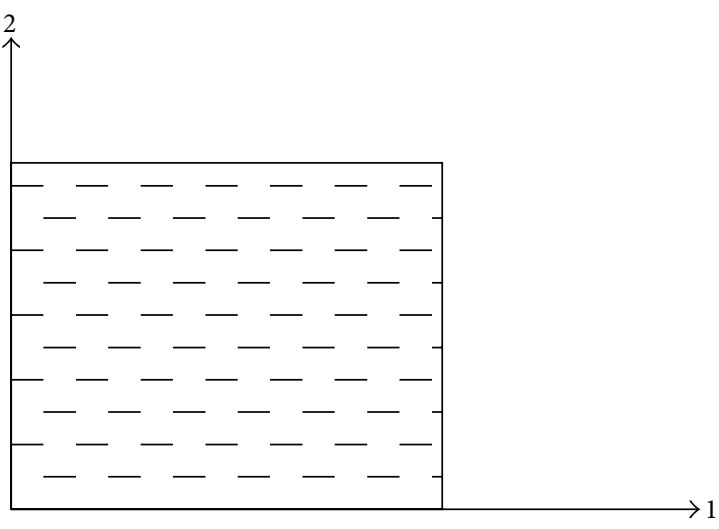

FIgURE 7: Unidirectional discontinuous fiber matrix.

where

$$
\begin{aligned}
& \eta_{l}=\frac{E_{s f} / E_{m}-1}{E_{s f} / E_{m}+2 \cdot a_{f}}, \\
& \eta_{T}=\frac{E_{s f} / E_{m}-1}{E_{s f} / E_{m}+2}, \\
& \eta_{G}=\frac{G_{s f} / G_{m}-1}{G_{s f} / G_{m}+1} .
\end{aligned}
$$

Let $E_{1 m}$ and $E_{2 m}$ be the longitudinal and transverse moduli defined by (6) and (7) for unidirectional fiber $0^{\circ}$ composite matrix of the same fiber aspect ratio and fiber volume fraction as the randomly oriented discontinuous fiber matrix shown in Figure 8. Since the fiber is randomly oriented, the matrix exhibits isotropic behavior. The Young and shear moduli of such a composite matrix are given by [22]

$$
\begin{aligned}
& E_{\mathrm{cm}}=\frac{3}{8} \cdot E_{1 m}+\frac{5}{8} \cdot E_{2 m}, \\
& G_{\mathrm{cm}}=\frac{1}{8} \cdot E_{1 m}+\frac{1}{4} \cdot E_{2 m} .
\end{aligned}
$$

Or they can be rewritten as

$$
G_{\mathrm{cm}}=\frac{E_{\mathrm{cm}}}{2\left(1+v_{\mathrm{cm}}\right)}
$$

or

$$
v_{\mathrm{cm}}=\left(\frac{E_{\mathrm{cm}}}{2 \cdot G_{\mathrm{cm}}}-1\right)
$$




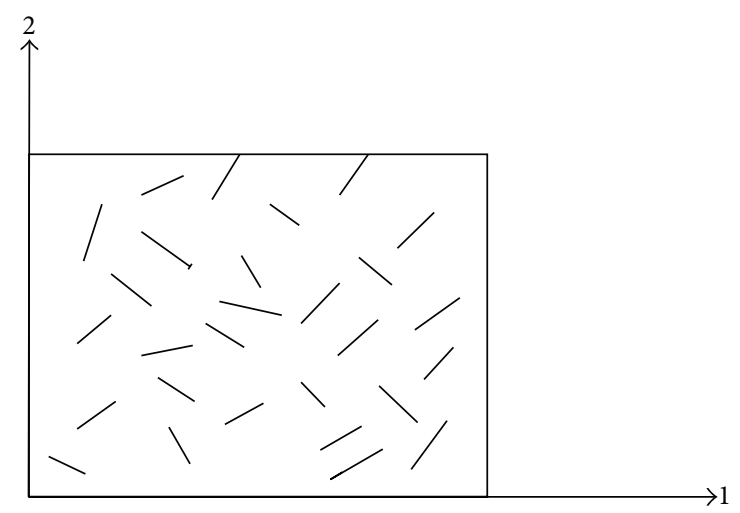

Figure 8: Randomly oriented discontinuous fiber-reinforced matrix.

The fractions $\forall_{s f m}$ and $\forall_{m m}$ are considered to be matrix; then

$$
\begin{gathered}
\forall_{s f m}+\forall_{m m}=1, \\
\forall_{s f m}+\forall_{m p}+\forall_{f}=1, \\
\forall_{m}+\forall_{f}=1, \quad \text { for } \forall_{s f p}+\forall_{m p}=\forall_{m}, \\
\forall_{s f m}=\frac{\left(\forall_{s f p}\right)}{\left(\forall_{s f p}+\forall_{m p}\right)}=\frac{\left(\forall_{s f p}\right)}{\left(\forall_{m}\right)}, \\
\forall_{m m}=\frac{\forall_{m p}}{\forall_{s f p}+\forall_{m p}}=\frac{\forall_{m p}}{\forall_{m}} .
\end{gathered}
$$

Then, using (21) in (6) through (10) results in

$$
\begin{aligned}
& E_{1 m}=\frac{1+2 \cdot a_{f} \cdot \eta_{l} \cdot\left(\forall_{s f m} / \forall_{m}\right)}{1-\eta_{l} \cdot\left(\forall_{s f m} / \forall_{m}\right)} \cdot E_{m}, \\
& E_{2 m}=\frac{1+2 \cdot \eta_{T} \cdot\left(\forall_{s f p} / \forall_{m}\right)}{1-\eta_{T} \cdot\left(\forall_{s f p} / \forall_{m}\right)} \cdot E_{m}, \\
& G_{12 m}=\frac{1+\eta_{G} \cdot\left(\forall_{s f p} / \forall_{m}\right)}{1-\eta_{G} \cdot\left(\forall_{s f m} / \forall_{m}\right)} \cdot G_{m}, \\
& v_{12 m}=v_{s f} \cdot \frac{\forall_{s f p}}{\forall_{m}}+v_{m} \frac{\forall_{m p}}{\forall_{m}},
\end{aligned}
$$

where $\eta_{l}, \eta_{T}$, and $\eta_{G}$ are as defined in (10) through (12).
Then, by substitution of (22) and (23) into (13), (14), and (16), one gets

$$
\begin{aligned}
E_{\mathrm{cm}}= & {\left[\left(\frac{3 \cdot\left(1-\forall_{f}\right)+6 \cdot a_{f} \cdot \eta_{l} \cdot \forall_{s f p}}{\left(1-\forall_{f}\right)-\eta_{l} \cdot \forall_{s f p}}\right)\right.} \\
& \left.+\left(\frac{5 \cdot\left(1-\forall_{f}\right)+10 \cdot \eta_{T} \cdot \forall_{s f p}}{\left(1-\forall_{f}\right)-\eta_{T} \cdot \forall_{s f p}}\right)\right] \cdot \frac{E_{m}}{8}, \\
G_{\mathrm{cm}}= & {\left[\left(\frac{\left(1-\forall_{f}\right)+2 \cdot a_{f} \cdot \eta_{l} \cdot \forall_{s f p}}{\left(1-\forall_{f}\right)-\eta_{l} \cdot \forall_{s f p}}\right)\right.} \\
& \left.+\left(\frac{2 \cdot\left(1-\forall_{f}\right)+4 \cdot \eta_{T} \cdot \forall_{s f p}}{\left(1-\forall_{f}\right)-\eta_{T} \cdot \forall_{s f p}}\right)\right] \cdot \frac{E_{m}}{8}, \\
v_{\mathrm{cm}}= & \left(\frac{E_{\mathrm{cm}}}{2 \cdot G_{\mathrm{cm}}}-1\right),
\end{aligned}
$$

where $E_{\mathrm{cm}}$ and $G_{\mathrm{cm}}$ are as defined above.

There are in all quantities $E_{c m}, G_{c m}$, and $v_{c m}$ to describe the elastic behavior of the composite matrix combination of discontinuous randomly oriented fibers and resin bonding material.

5.2. Hybrid Composite Lamina (Discontinuous Random Short Fiber, Resin, and Continuous Fiber). Figure 8 shows a simple schematic model of a composite lamina consisting of discontinuous random fiber, resin, and continuous fiber. The fibers are assumed to be uniformly distributed throughout the composite matrix, composed of discontinuous random short fiber and resin material. A perfect bonding is assumed to be free of any voids. The fibers and the matrix are both assumed to be linear and elastic. The elastic analysis of such a lamina will be as follows [21]:

$$
\begin{gathered}
\varepsilon_{f}=\mathscr{E}_{\mathrm{cm}}+\mathscr{E}_{c}, \\
\sigma_{f}=E_{f} \cdot \mathscr{E}_{f}=E_{f} \cdot \mathscr{E}_{c}, \\
\sigma_{m}=E_{\mathrm{cm}} \cdot \mathscr{E}_{\mathrm{cm}}=E_{\mathrm{cm}} \cdot \mathscr{E}_{c} \\
P=P_{f}+P_{\mathrm{cm}} \\
\sigma_{c} A_{c}=\sigma_{f} \cdot A_{f}+\sigma_{m} \cdot A_{m}, \\
\sigma_{c}=\frac{1}{A_{c}}\left(\sigma_{f} \cdot A_{f}+\sigma_{m} \cdot A_{m}\right)=\sigma_{f} \cdot \forall_{f}+\sigma_{m} \cdot \forall_{m}, \\
\forall_{f}=\frac{A_{f}}{A_{c}}, \quad \forall_{m}=\forall_{s f p}+\forall_{m p}=\left(1-\forall_{f}\right)=\frac{A_{m}}{A_{c}} .
\end{gathered}
$$

Then, the longitudinal modulus of the lamina is given by

$$
E_{1}=\frac{\sigma_{c}}{\mathscr{E}_{c}}=E_{f} \cdot \forall_{f}+E_{\mathrm{cm}} \cdot\left(1-\forall_{f}\right) .
$$

By using (21) in (27) one gets

$$
E_{1}=E_{f} \cdot \forall_{f}+\left(1-\forall_{f}\right)\left[\frac{3}{8} E_{1 m}+\frac{5}{8} E_{2 m}\right]
$$


or

$$
\begin{aligned}
E_{1}=E_{f} \cdot \forall_{f}+\left(1-\forall_{f}\right) \cdot E_{m} \\
\times\left[\left(\frac{3 \cdot\left(1-\forall_{f}\right)+6 \cdot a_{f} \cdot \eta_{l} \cdot \forall_{s f p}}{8\left(1-\forall_{f}\right)-8 \eta_{l} \cdot \forall_{s f p}}\right)\right. \\
\left.+\left(\frac{5 \cdot\left(1-\forall_{f}\right)+10 \cdot \eta_{T} \cdot \forall_{s f p}}{8\left(1-\forall_{f}\right)-8 \eta_{T} \cdot \forall_{s f p}}\right)\right] .
\end{aligned}
$$

The corresponding major Poisson ratio is

$$
v_{12}=v_{f} \cdot \forall_{f}+v_{\mathrm{cm}}\left(1-\forall_{f}\right) .
$$

Using (26) and (13) in (37) results in

$$
v_{12}=v_{f} \cdot \forall_{f}+\left(\frac{E_{\mathrm{cm}}}{2 \cdot G_{\mathrm{cm}}}-1\right)\left(1-\forall_{f}\right) .
$$

The transverse modulus and minor Poisson's ratio for the loading transverse to the continuous fiber direction as shown in Figures 9(a) and 9(b) are

$$
\begin{aligned}
& E_{2}=\frac{E_{f} \cdot E_{\mathrm{cm}}}{E_{f}\left(1-V_{f}\right)+E_{\mathrm{cm}} \cdot V_{f}} \text { or } \\
& E_{2}=E_{f} \cdot E_{\mathrm{cm}}\left[\left(\frac{3 \cdot\left(1-\forall_{f}\right)+6 \cdot a_{f} \cdot \eta_{l} \cdot \forall_{s f p}}{8\left(1-\forall_{f}\right)-8 \eta_{l} \cdot \forall_{s f p}}\right)\right. \\
& \left.+\left(\frac{5 \cdot\left(1-\forall_{f}\right)+10 \cdot \eta_{T} \cdot \forall_{s f p}}{8\left(1-\forall_{f}\right)-8 \eta_{T} \cdot \forall_{s f p}}\right)\right] \\
& \times\left(E_{f}\left(1-\forall_{f}\right)+E_{\mathrm{cm}} \cdot \forall_{f}\right. \\
& \times\left[\left(\frac{3 \cdot\left(1-\forall_{f}\right)+6 \cdot a_{f} \cdot \eta_{l} \cdot \forall_{s f p}}{8\left(1-\forall_{f}\right)-8 \eta_{l} \cdot \forall_{s f p}}\right)\right. \\
& \left.\left.+\left(\frac{5 \cdot\left(1-\forall_{f}\right)+10 \cdot \eta_{T} \cdot \forall_{s f p}}{8\left(1-\forall_{f}\right)-8 \eta_{T} \cdot \forall_{s f p}}\right)\right]\right)^{-1}, \\
& v_{21}=\frac{E_{2}}{E_{1}} v_{12}
\end{aligned}
$$

where $E_{1}, E_{2}$, and $v_{12}$ are as in (36), (38), and (39).

For a shear force loading as shown in Figures 9(a) and 9(b),

$$
G_{12}=\frac{G_{f} \cdot G_{\mathrm{cm}}}{G_{f} \cdot \forall_{m}+G_{\mathrm{cm}} \cdot \forall_{f}}=\frac{G_{f} \cdot G_{\mathrm{cm}}}{G_{f}\left(1-\forall_{f}\right)+G_{\mathrm{cm}} \cdot \forall_{f}} .
$$

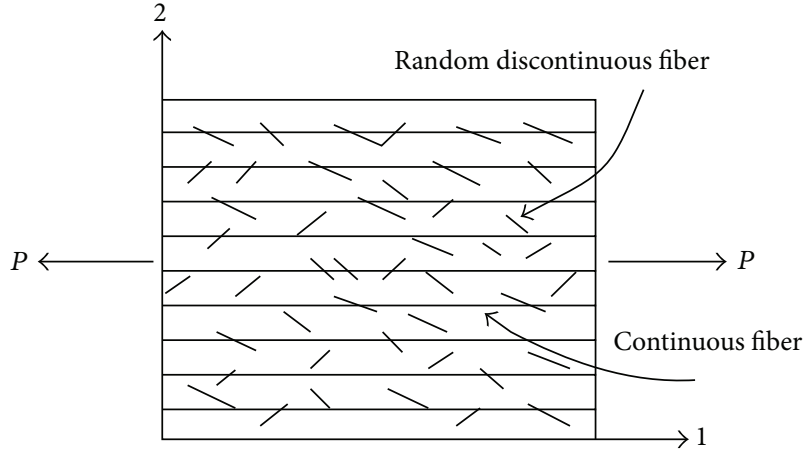

(a)

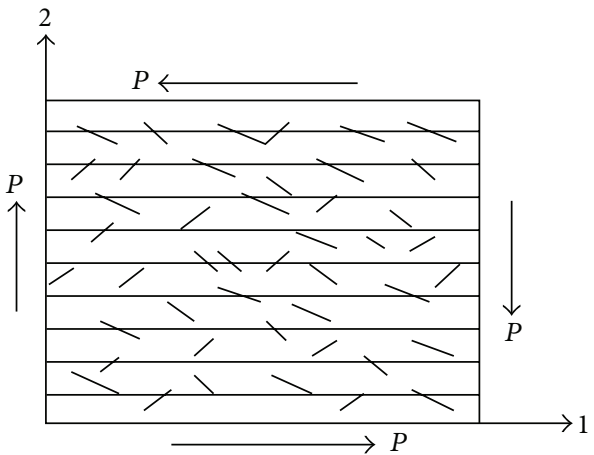

(b)

FIGURE 9: Unidirectional continuous fiber $\left(0^{\circ}\right)$ lamina.

Substitution of (26) into (41) leads to

$$
\begin{array}{r}
G_{12}=G_{f} \cdot E_{m} \cdot\left[\left(\frac{\left(1-\forall_{f}\right)+2 \cdot a_{f} \cdot \eta_{l} \cdot \forall_{s f p}}{\left.\left(1-\forall_{f}\right)-\eta_{l} \cdot \forall_{s f p}\right)}\right)\right. \\
\left.+\left(\frac{2 \cdot\left(1-\forall_{f}\right)+4 \cdot \eta_{T} \cdot \forall_{s f p}}{\left.\left(1-\forall_{f}\right)-\eta_{T} \cdot \forall_{s f p}\right)}\right)\right] \\
\times\left(8 \cdot G_{f} \cdot\left(1-\forall_{f}\right)\right. \\
+E_{m} \cdot \forall_{f}\left[\left(\frac{\left(1-\forall_{f}\right)+2 \cdot a_{f} \cdot \eta_{l} \cdot \forall_{s f p}}{\left(1-\forall_{f}\right)-\eta_{l} \cdot \forall_{s f p}}\right)\right. \\
\left.\left.\quad+\left(\frac{2 \cdot\left(1-\forall_{f}\right)+4 \cdot \eta_{T} \cdot \forall_{s f p}}{\left(1-\forall_{f}\right)-\eta_{T} \cdot \forall_{s f p}}\right)\right]\right)^{-1} .
\end{array}
$$

There are in all quantities $E_{1}, E_{2}, G_{12}$, and $v_{12}$ to describe the elastic behavior of a hybrid lamina composed of composite matrix and continuous reinforcement fibers.

Some of the effective elastic properties of the hybrid composite materials considered in this work based on the analysis above are tabulated in Table 1. 
TABLE 1: Some of the elastic properties of some hybrid composites considered.

\begin{tabular}{lccccccc}
\hline Number & Hybrid composite & $E_{1}\left(\mathrm{~N} / \mathrm{m}^{2}\right)$ & $E_{2}=E_{3}\left(\mathrm{~N} / \mathrm{m}^{2}\right)$ & $v_{21}=v_{31}$ & $v_{23}=v_{32}$ & $G_{12}=G_{13}\left(\mathrm{~N} / \mathrm{m}^{2}\right)$ & $G_{23}=G_{32}\left(\mathrm{~N} / \mathrm{m}^{2}\right)$ \\
\hline 1 & K49-epoxy1 & $5.37 E+10$ & $9.89 E+09$ & $7.20 E-02$ & $5.95 E-01$ & $2.41 E+09$ & $3.10 E+09$ \\
2 & K49-epoxy2 & $5.64 E+10$ & $1.69 E+10$ & $1.21 E-01$ & $5.95 E-01$ & $3.39 E+09$ & $5.31 E+09$ \\
3 & K49-epoxy3 & $5.94 E+10$ & $2.40 E+10$ & $1.65 E-01$ & $5.78 E-01$ & $4.07 E+09$ & $7.60 E+09$ \\
4 & K49-epoxy4 & $6.24 E+10$ & $3.11 E+10$ & $2.05 E-01$ & $5.57 E-01$ & $4.59 E+09$ & $9.98 E+09$ \\
5 & Boron-epoxy1 & $1.59 E+11$ & $1.98 E+10$ & $5.15 E-02$ & $6.65 E-01$ & $6.79 E+09$ & $5.96 E+09$ \\
6 & Boron-epoxy2 & $1.66 E+11$ & $3.74 E+10$ & $9.53 E-02$ & $6.60 E-01$ & $1.28 E+10$ & $1.13 E+10$ \\
7 & Boron-epoxy3 & $1.73 E+11$ & $5.56 E+10$ & $1.37 E-01$ & $6.39 E-01$ & $1.90 E+10$ & $1.70 E+10$ \\
8 & Boron-epoxy4 & $1.81 E+11$ & $7.45 E+10$ & $1.76 E-01$ & $6.14 E-01$ & $2.55 E+10$ & $2.31 E+10$ \\
9 & E-glass-epoxy1 & $3.54 E+10$ & $7.68 E+09$ & $7.12 E-02$ & $4.54 E-01$ & $2.71 E+09$ & $2.64 E+09$ \\
10 & E-glass-epoxy2 & $3.74 E+10$ & $1.25 E+10$ & $1.14 E-01$ & $4.60 E-01$ & $4.37 E+09$ & $4.29 E+09$ \\
11 & E-glass-epoxy3 & $3.94 E+10$ & $1.73 E+10$ & $1.53 E-01$ & $4.52 E-01$ & $6.04 E+09$ & $5.97 E+09$ \\
12 & E-glass-epoxy4 & $4.15 E+10$ & $2.22 E+10$ & $1.88 E-01$ & $4.40 E-01$ & $7.74 E+09$ & $7.71 E+09$ \\
\hline
\end{tabular}

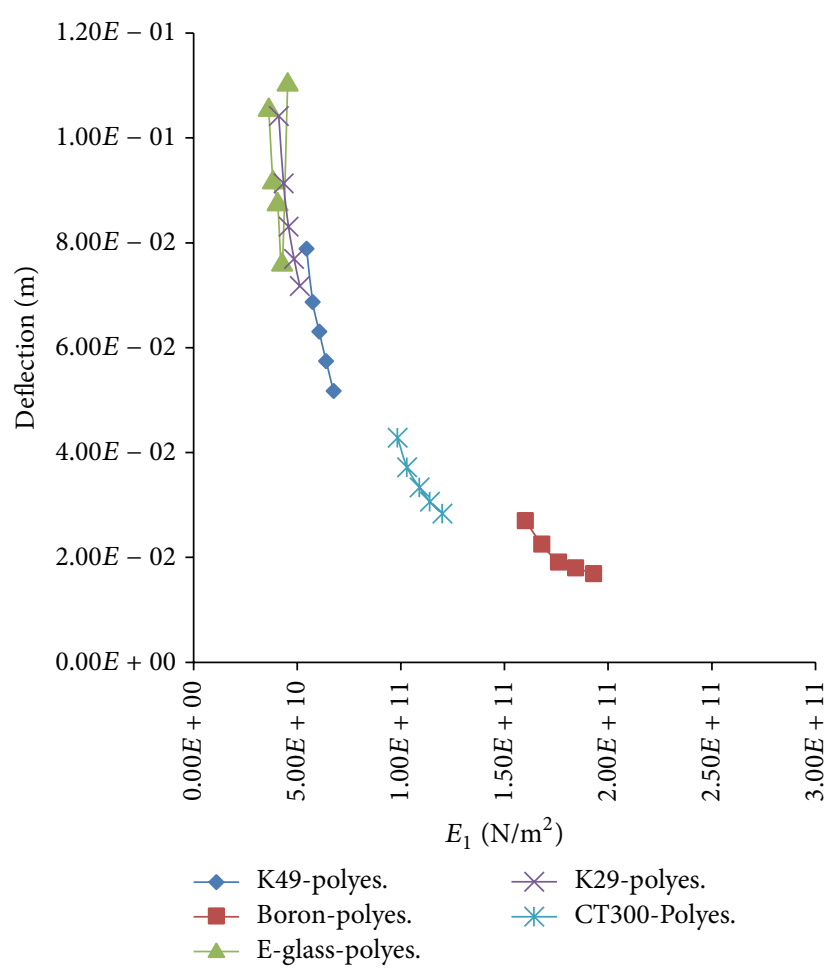

FIGURE 10: Effect of longitudinal modulus of elasticity on leaf spring deflection of various composite leaf springs based on matrix type.

\section{Results and Discussion}

As it is seen from (4), both maximum deflection and maximum bending stress depend on the longitudinal modulus of elasticity $\left(E_{1}\right)$ which itself is affected by the constituents' mixing schemes and their volume fractions. Plotted figures clearly explain the effects of fibers only, matrices only, and fiber volume fractions, each of which on the leaf spring responses. For the deflection, it is more highly affected by fibers type than matrix type. Figures 10 through 12 show the effect of matrix variation with the same group of fibers; they all exhibit the same behavior against load application

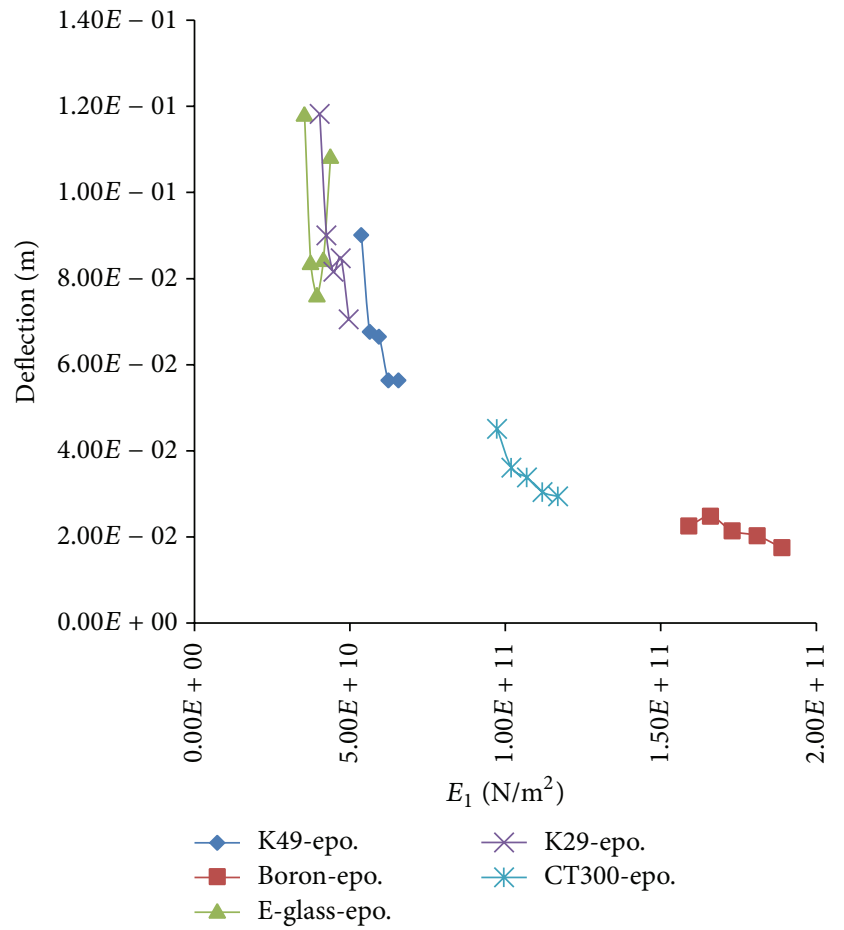

FIGURE 11: Effect of longitudinal modulus of elasticity on leaf spring deflection of various composite leaf springs based on matrix type.

except that for E-glass group as it irregularly behaves for all of its collections with different matrices; therefore it may be suggested to make use of the other four types of fibers in case of selecting them as constituents in hybrid fiber-reinforced composite leaf springs. It can also be clearly seen that the more the higher longitudinal modulus of elasticity of a fiber is, the more the lower deflection of a spring is.

A more accurate indication can be obtained when Figures $13,14,15,16$, and 17 are examined to explore the predominant effect of fibers on leaf springs performance such that the irregular behavior of E-glass appears more clearly in Figure 14 with two matrices (epoxy and polyester) except 


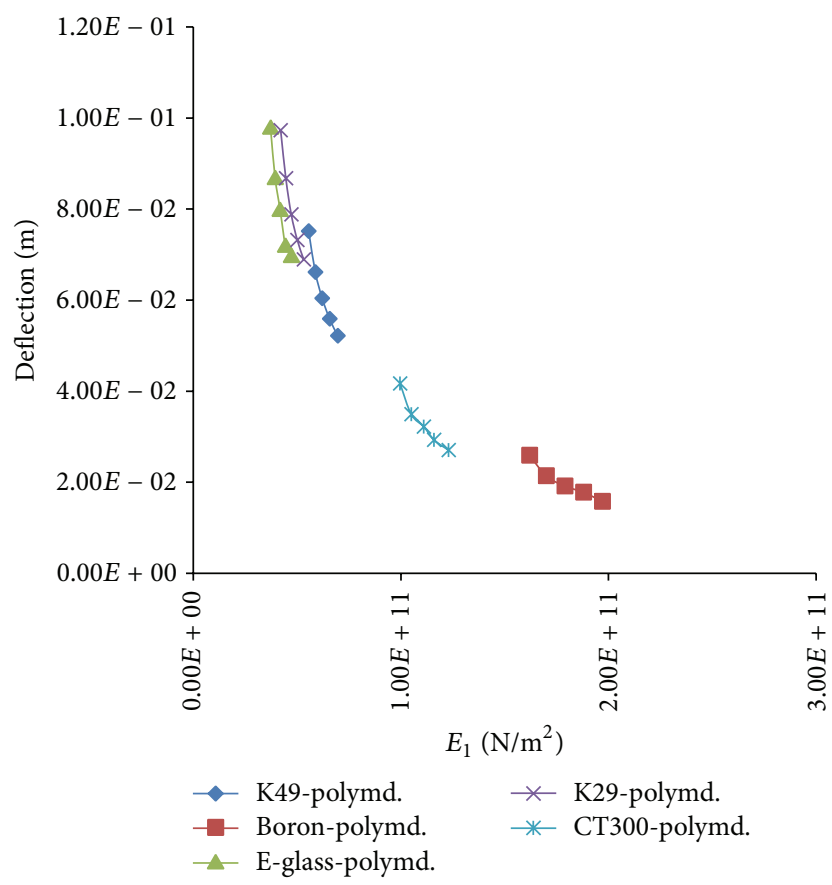

FIGURE 12: Effect of longitudinal modulus of elasticity on leaf spring deflection of various composite leaf springs based on matrix type.

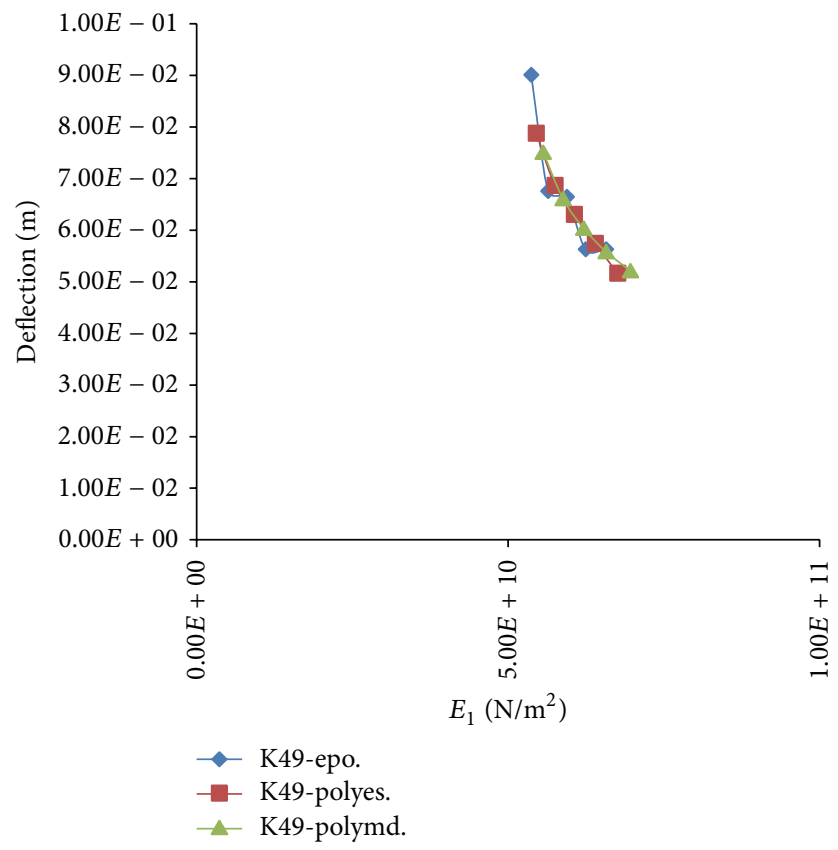

FIGURE 13: Effect of longitudinal modulus of elasticity on leaf spring deflection of various composite leaf springs based on fiber type.

with polyamide, but this is not the case when E-glass is introduced in simple traditional fiber-reinforced composite materials $[24,25]$; this may be due to hybridization effect with respect to E-glass particularly, consolidating what has already been mentioned in Figures 10 and 11. Other fibers maintain uniform behavior analytically and numerically

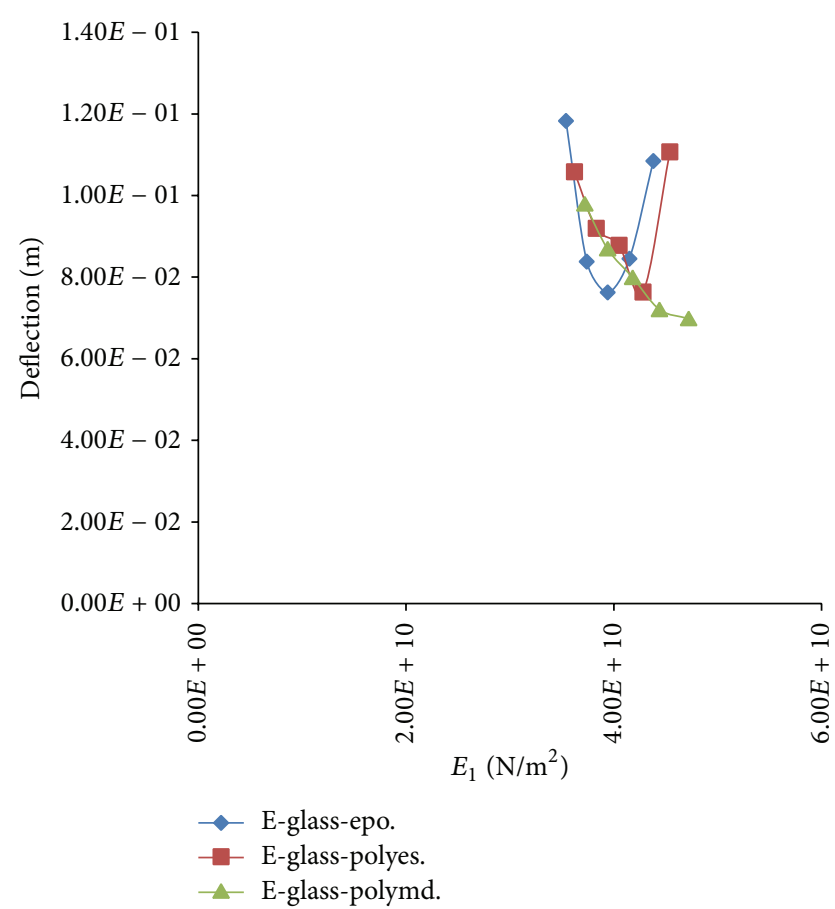

FIGURE 14: Effect of longitudinal modulus of elasticity on leaf spring deflection of various composite leaf springs based on fiber type.

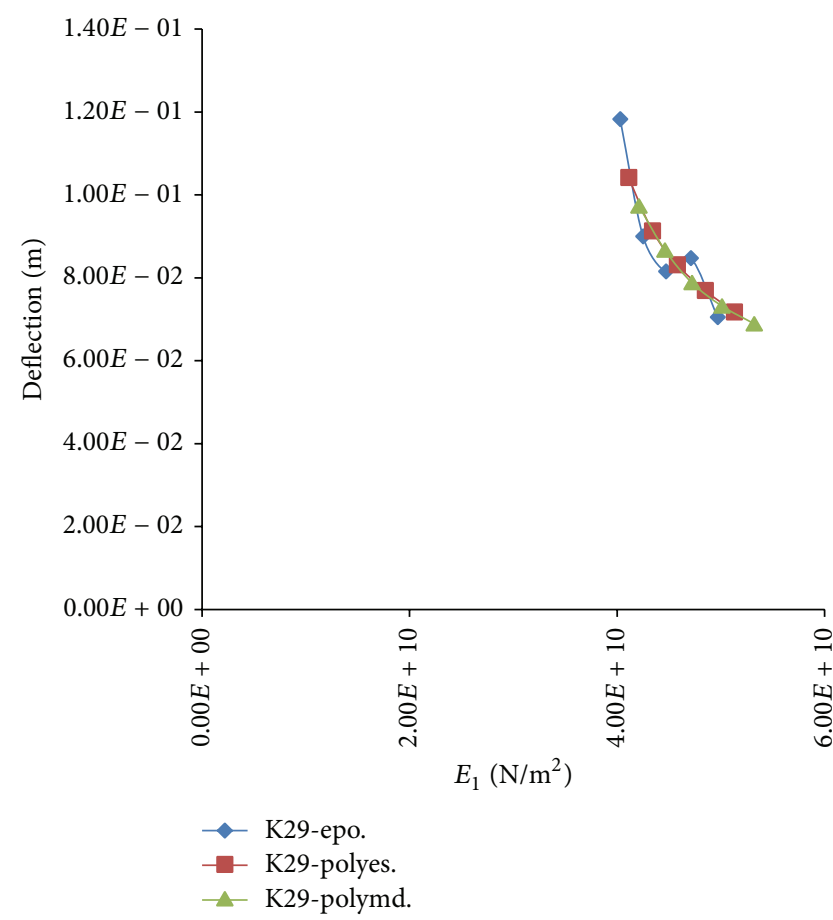

FIGURE 15: Effect of longitudinal modulus of elasticity on leaf spring deflection of various composite leaf springs based on fiber type.

with all matrices. The predominance of fibers effect can be attributed to mainly their high modulus of elasticity affecting the macroscopic flexural and bending stiffness of the hybrid composite structure as a whole. Bending stresses are investigated under the same conditions as of the deflections. Figures 18 and 19 show the variation of bending stresses induced in 


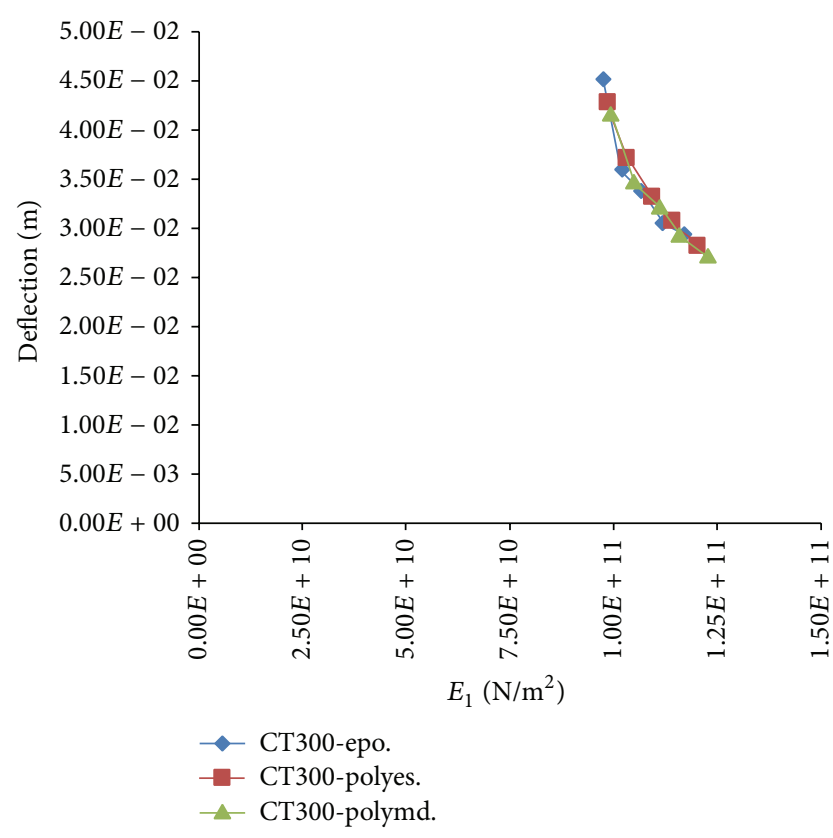

FIGURE 16: Effect of longitudinal modulus of elasticity on leaf spring deflection of various composite leaf springs based on fiber type.

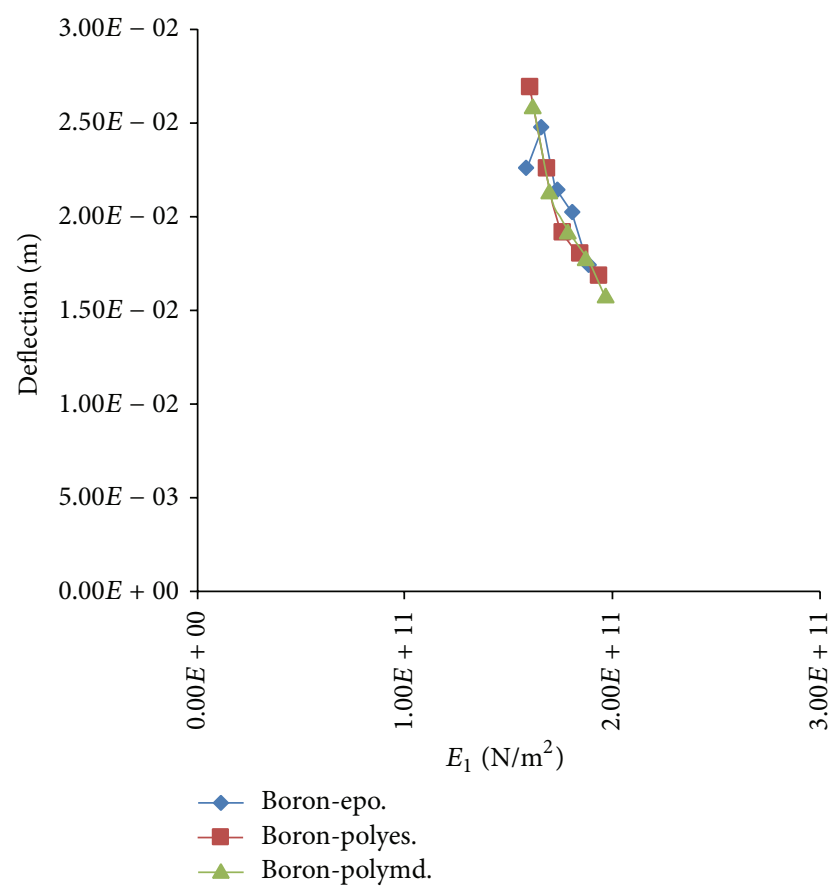

FIGURE 17: Effect of longitudinal modulus of elasticity on leaf spring deflection of various composite leaf springs based on fiber type.

the structure according to fiber variation with the same matrix. An inverse proportionality is displayed between the increase of longitudinal modulus of elasticity of the hybrid composite structure (which is highly affected by the fiber type) and the magnitude of the bending stresses induced, since the bending stiffness of the structure $\left(E_{1} I\right)$ increases with increase of $E_{1}$, expressing the maximization of

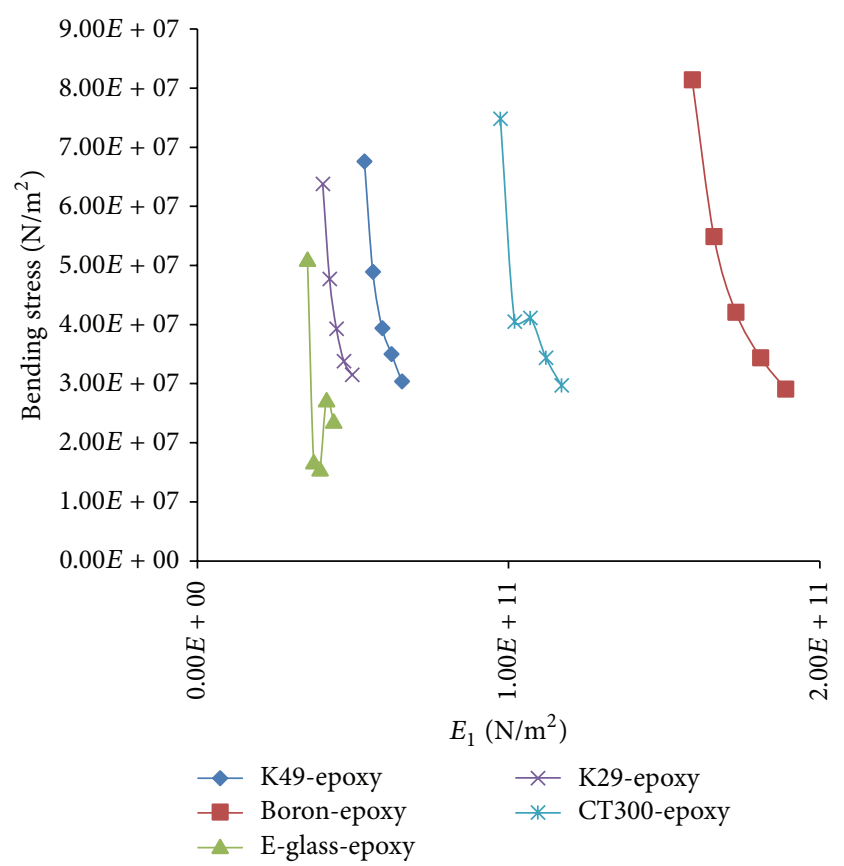

FIGURE 18: Effect of longitudinal modulus of elasticity on bending stresses of various composite leaf springs based on matrix type.

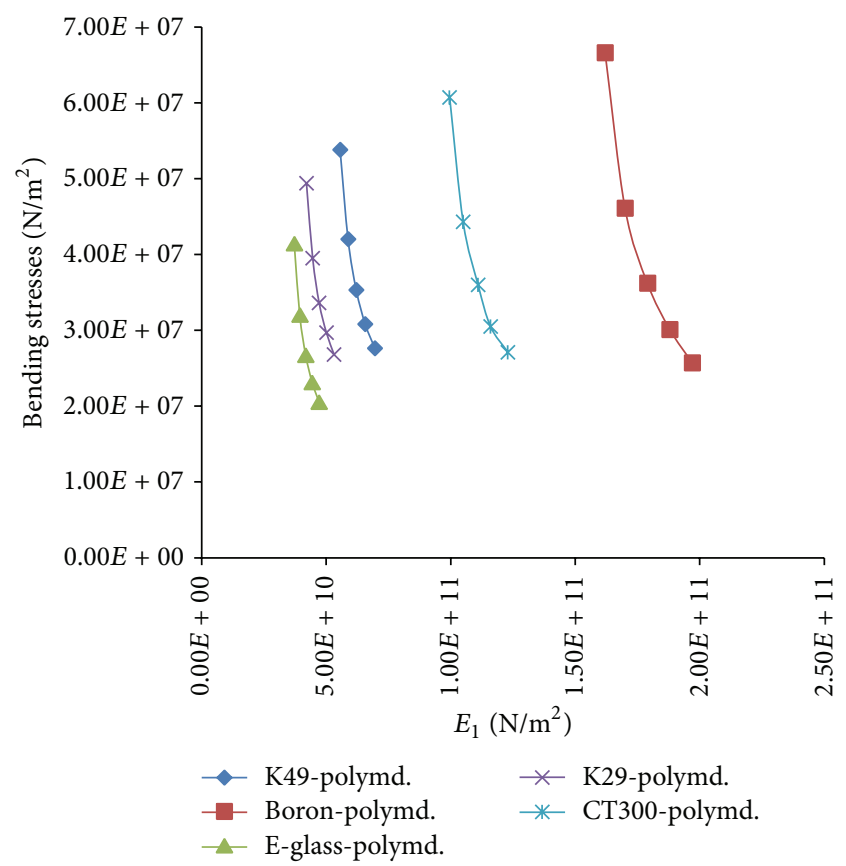

FIGURE 19: Effect of longitudinal modulus of elasticity on bending stresses of various composite leaf springs based on matrix type.

the bending strength of the structure. All of the hybrid composites collections reveal the same overall behavior numerically and analytically for both deflections and bending stresses values. As the fiber volume fraction increases the conformity between the results increases up to $94 \%$ as it is clearly noticed through Figures 20 and 21, referring to the validity of the results. 


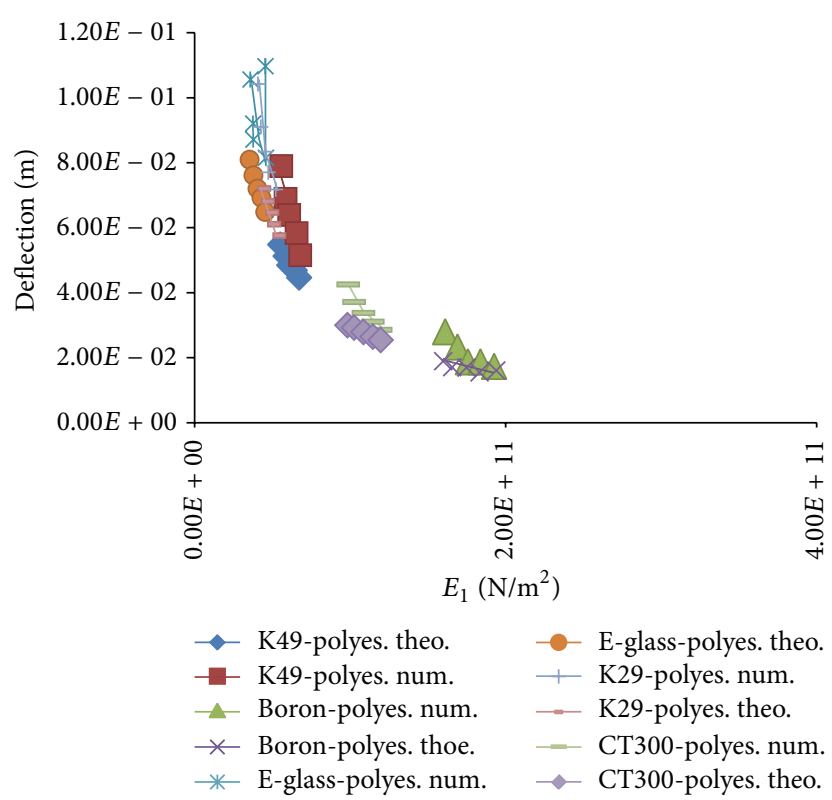

Figure 20: Comparison of numerical and theoretical results of effect of $E_{1}$ on spring deflection based on fibers variation with polyester.

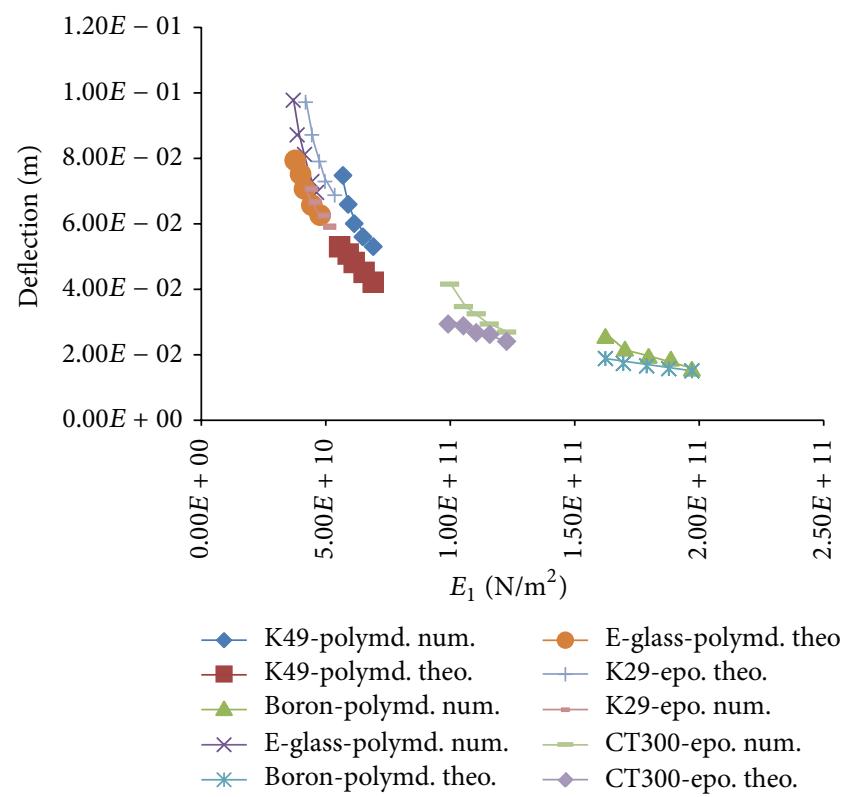

FIGURE 21: Comparison of numerical and theoretical results of effect of $E_{1}$ on spring deflection based on fibers variation with polyamide.

\section{Verification of the Results}

A comparison has been made among the numerical results obtained from the FEA made by the ANSYS software and their corresponding theoretical counterparts as a means of proofing the validity and authenticity of the manipulation and solution of the problem. Referring to (4), there is an inverse proportionality between $E_{1}$ and the deflection of the hybrid leaf spring and it is seen from Figures 20 and 21 that the nature of variation of deflection is identical and the ratio of conformity is ranging from $63 \%$ at low fiber volume fraction of $6 \%$ of short fibers constituting the composite matrix of K49/epoxy up to $99 \%$ at a fiber volume fraction of $18 \%$ of short fibers constituting the composite matrix of Eglass/epoxy. But as a general case a ratio of more than $80 \%$ is obtained between both results. Figures 20 and 21 graphically show in detail the convergence of various comparisons for various hybrid composites.

\section{Conclusions}

From the above discussion, the following conclusions can be made.

(1) Fibers are the most predominant and controlling element on the bending stiffness of the structure.

(2) For heavier trucks, hybrid composite springs of higher longitudinal moduli of elasticity fibers should be adopted instead of using multilayer softer ones for the sake of

(a) total weight reduction of a truck;

(b) easiness and quickness of fabrication, manufacturing, and maintenance;

(c) economy of maintenance.

(3) E-glass fiber in the hybrid composites does not exhibit a regular behavior making it difficult to accurately predict hybrid composite spring performance, response, and stresses, while boron is the opposite; thus it is advisable to adopt it in such applications with various matrices.

\section{Nomenclature}

$E_{1 m}$ : Longitudinal moduli for a unidirectional discontinuous fiber $0^{\circ}$ composite matrix, composed of resin and discontinuous fiber

$E_{2 m}$ : Transverse moduli for a unidirectional discontinuous fiber $0^{\circ}$ composite matrix, composed of resin and discontinuous fiber

$E_{\mathrm{cm}}$ : Moduli of isotropic composite matrix, composed of resin and random discontinuous fiber

$E_{1}$ : Longitudinal modulus for unidirectional continuous fiber $0^{\circ}$ composite lamina, composed of composite matrix and continuous fiber

$E_{2}$ : Transverse modulus for unidirectional continuous fiber $0^{\circ}$ composite lamina, composed of composite matrix and continuous fiber

$E_{s f}:$ Moduli of discontinuous fiber material

$E_{f}$ : Moduli of continuous fiber material

$E_{m}: \quad$ Moduli of resin material

$G_{12 m}$ : Shear modulus for a unidirectional discontinuous fiber $0^{\circ}$ composite matrix 
$G_{\mathrm{cm}}$ : Shear modulus of isotropic composite matrix

$G_{12}$ : Shear modulus for a unidirectional continuous fiber $0^{\circ}$ composite lamina

$G_{s f}$ : Shear modulus of discontinuous fiber material

$G_{f}$ : Shear modulus of continuous fiber material

$G_{m}$ : Shear of resin material

$\nu_{12 m}$ : The major Poisson ratio for a unidirectional discontinuous fiber $0^{\circ}$ composite matrix

$v_{\mathrm{cm}}$ : Poisson's ratio of isotropic composite matrix

$v_{12}$ : The major Poisson ratio for a unidirectional continuous fiber $0^{\circ}$ composite lamina

$v_{s f}$ : Poisson's ratio for discontinuous fiber material

$v_{f}$ : Poisson's ratio for continuous fiber

$v_{m}$ : Poisson's ratio for resin material

$\forall_{s f p}$ : Volume fraction of discontinuous fiber, ratio of the volume of discontinuous fiber to the volume of composite lamina

$\forall_{m m}$ : Volume fraction of resin matrix, ratio of the volume of resin to the volume of composite matrix

$\forall_{m p}$ : Volume fraction of resin matrix, ratio of the volume of resin to the volume of composite lamina

$\forall_{f}$ : Volume fraction of continuous fiber, ratio of the volume of continuous fiber to the volume of composite lamina

$\forall_{m}$ : Volume fraction of matrix, ratio of the volume of composite matrix to the volume of composite lamina

$a_{f}$ : The ratio of average fiber length to fiber diameter $=l f / d f$, which is taken to be 500 for the purpose of elastic properties calculations of hybrid composite matrix and material [26]

$d_{f}$ : Fiber diameter

$l_{f}$ : Average fiber length.

\section{Conflict of Interests}

The author declares that there is no conflict of interests regarding the publication of this paper.

\section{References}

[1] G. H. Gowd and E. V. Goud, "Static analysis of leaf spring," International Journal of Engineering Science and Technology, vol. 4, no. 8, 2012.

[2] D. Ashok, M. V. Mallikarjun, and V. R. Mamilla, "Design and structural analysis of composite multi leaf spring," International Journal of Emerging trends in Engineering and Development, vol. 5, no. 2, 2012, http://www.rspublication.com/ijeted/ ijeted_index.htm.
[3] I. Rajendran and S. Vijayarangan, "Optimal design of a composite leaf spring using genetic algorithms," Computers and Structures, vol. 79, no. 11, pp. 1121-1129, 2001.

[4] K. K. Jadhao and R. S. Dalu, "Experimental investigation \& numerical analysis of composite leaf spring," International Journal of Engineering Science and Technology, vol. 3, no. 6, pp. 4759-4764, 2011.

[5] M. Raghavedra, S. A. Hussain, V. Pandurangadu, and K. PalaniKumar, "Modeling and analysis of laminated composite leaf spring under the static load condition by using FEA," International Journal of Modern Engineering Research (IJMER), vol. 2, no. 4, pp. 1875-1879, 2012.

[6] Y. N. V. Santhosh Kumar and M. Vimal Teja, "Design and analysis of composite leaf spring in light vehicle," International Journal of Mechanical and Industrial Engineering, vol. 2, no. 1, pp. 213-218, 2012.

[7] S. Kumar and S. Vijayarangan, "Analytical and experimental studies on fatigue life prediction of steel and composite multileaf spring for light passenger vehicles using life data analysis," Material Science, vol. 13, no. 2, pp. 141-146, 2007.

[8] Z. Yang and Z. Wang, "Cyclic creep and cyclic deformation of high-strength spring steels and the evaluation of the sag effect: part I: cyclic plastic deformation behavior," Metallurgical and Materials Transactions A, vol. 32, no. 7, pp. 1687-1698, 2001.

[9] J. J. Fuentes, H. J. Aguilar, J. A. Rodríguez, and E. J. Herrera, "Premature fracture in automobile leaf springs," Engineering Failure Analysis, vol. 16, no. 2, pp. 648-655, 2009.

[10] C. K. Clarke and G. E. Borowski, "Evaluation of a leaf spring failure," ASM International, Journal of Failure Analysis and Prevention, vol. 5, no. 6, pp. 54-63, 2005.

[11] R. M. Mayer, J. P. Hou, J. Y. Cherruault, I. Nairne, and G. Jeronimidis, "Evolution of the eye-end design of a composite leaf spring for heavy axle loads," Composite Structures, vol. 64, pp. 351-358, 2007.

[12] M. M. Patunkar and D. R. Dolas, "Modelling and analysis of composite leaf spring under the static load condition by using FEA," International Journal of Mechanical \& Industrial Engineering, vol. 1, no. 1, 2011.

[13] K. Kumar and M. L. Aggarwal, "Computer aided FEA simulation of EN45A parabolic leaf spring," International Journal of Industrial Engineering Computations, vol. 4, no. 2, pp. 297-304, 2013.

[14] G. S. Shiva Shankar and S. Vijayarangan, "Mono composite leaf spring for light weight vehicle-design, end joint analysis and testing," Materials Science, vol. 12, no. 3, pp. 220-225, 2006.

[15] A. C. Baviskar, V. G. Bhamre, and S. S. Sarode, "Design and Analysis of a Leaf Spring for automobile suspension system: a review," International Journal of Emerging Technology and Advanced Engineering, vol. 3, no. 6, pp. 407-410, 2013.

[16] A. A. Satpute and S. S. Chavan, "Mono composite leaf springdesign and testing," Indian Journal of Applied Research, vol. 3, no. 7, 2013.

[17] G. H. Staab, Laminar Composites, Butterworth-Heinemann, Woburn, Mass, USA, 1999.

[18] B. B. Deshmukh and S. B. Jaju, "Design and analysis of glass fiber reinforced polymer (GFRP) leaf spring," in Proceedings of the 4th International Conference on Emerging Trends in Engineering and Technology (ICETET '11), pp. 82-87, November 2011.

[19] R. B. Charde and D. V. Bhope, "Investigation of stresses in master leaf of leaf spring by FEM and its experimental verification," International Journal of Engineering Science and Technology, vol. 4, no. 2, 2012. 
[20] V. Jadhav Mahesh, B. Zoman Digambar, Y. R. Kharde, and R. R. Kharde, "Performance analysis of two mono leaf spring used for maruti 800 vehicle," International Journal of Innovative Technology and Exploring Engineering, vol. 2, no. 1, pp. 65-67, 2012.

[21] R. M. Jones, Mechanics of Composite Materials, Scripta Book, Washington, DC, USA, 1999.

[22] J. S. Rao, Dynamic of Plate, Narosa Publishing House, 1999.

[23] A. B. Londhe, "FEA and analytical analysis of natural fibers composite leaf spring," International Journal of Mechanical Engineering and Research, vol. 3, no. 4, pp. 355-360, 2013.

[24] M. M. Shokrieh and D. Rezaei, "Analysis and optimization of a composite leaf spring," Composite Structures, vol. 60, no. 3, pp. 317-325, 2003.

[25] U. S. Ramakanth and K. Sowjanya, "Design and analysis of automotive multi-leaf springs using composite materials," International Journal of Mechanical, Production Engineering Research and Development, vol. 3, no. 1, pp. 155-162, 2013.

[26] M. Nanko, "Definitions and categories of hybrid materials," The AZo Journal of Materials Online, vol. 6, 2009. 

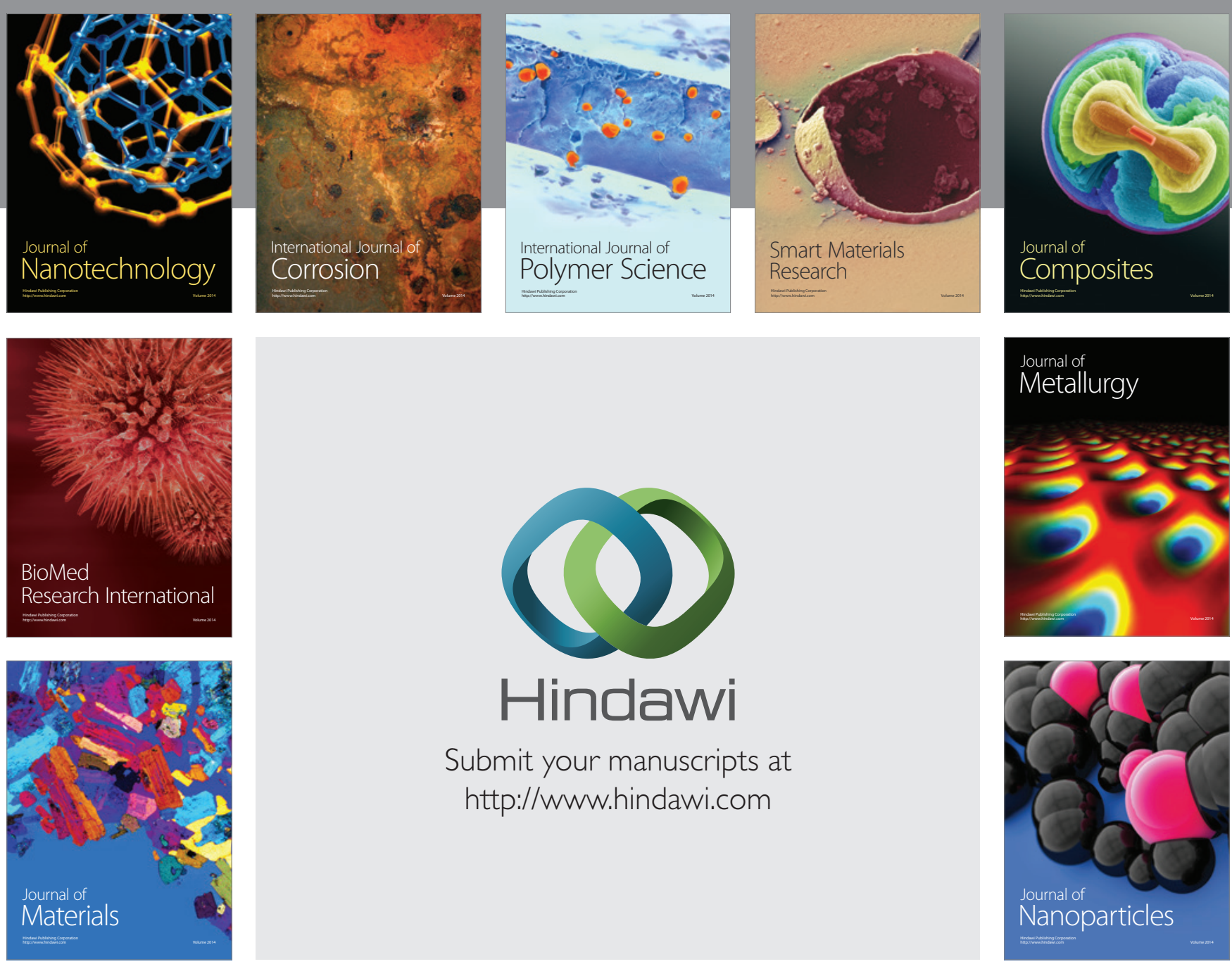

Submit your manuscripts at http://www.hindawi.com
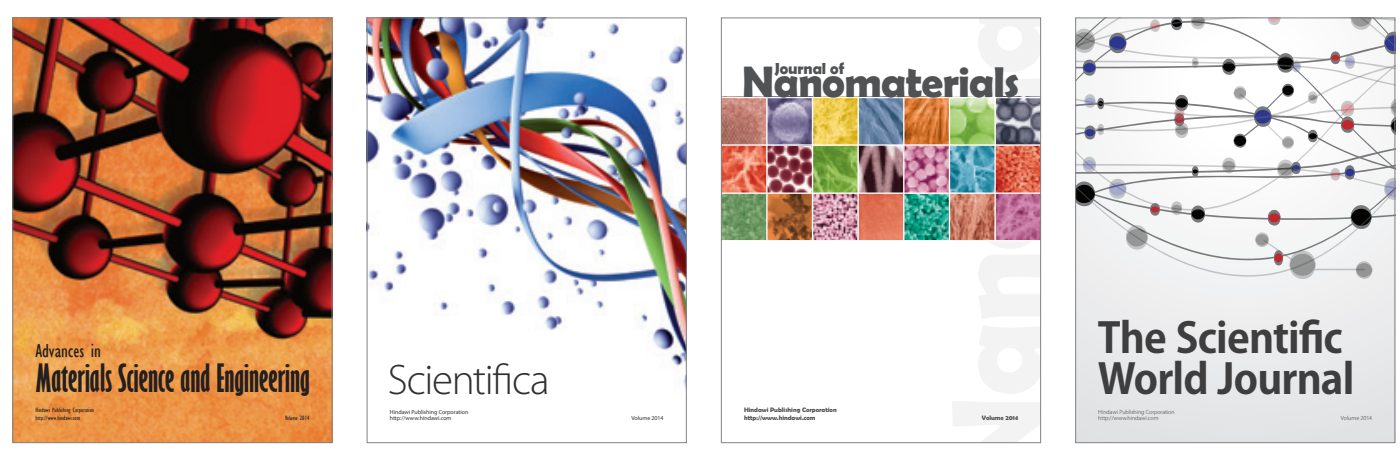

\section{The Scientific World Journal}
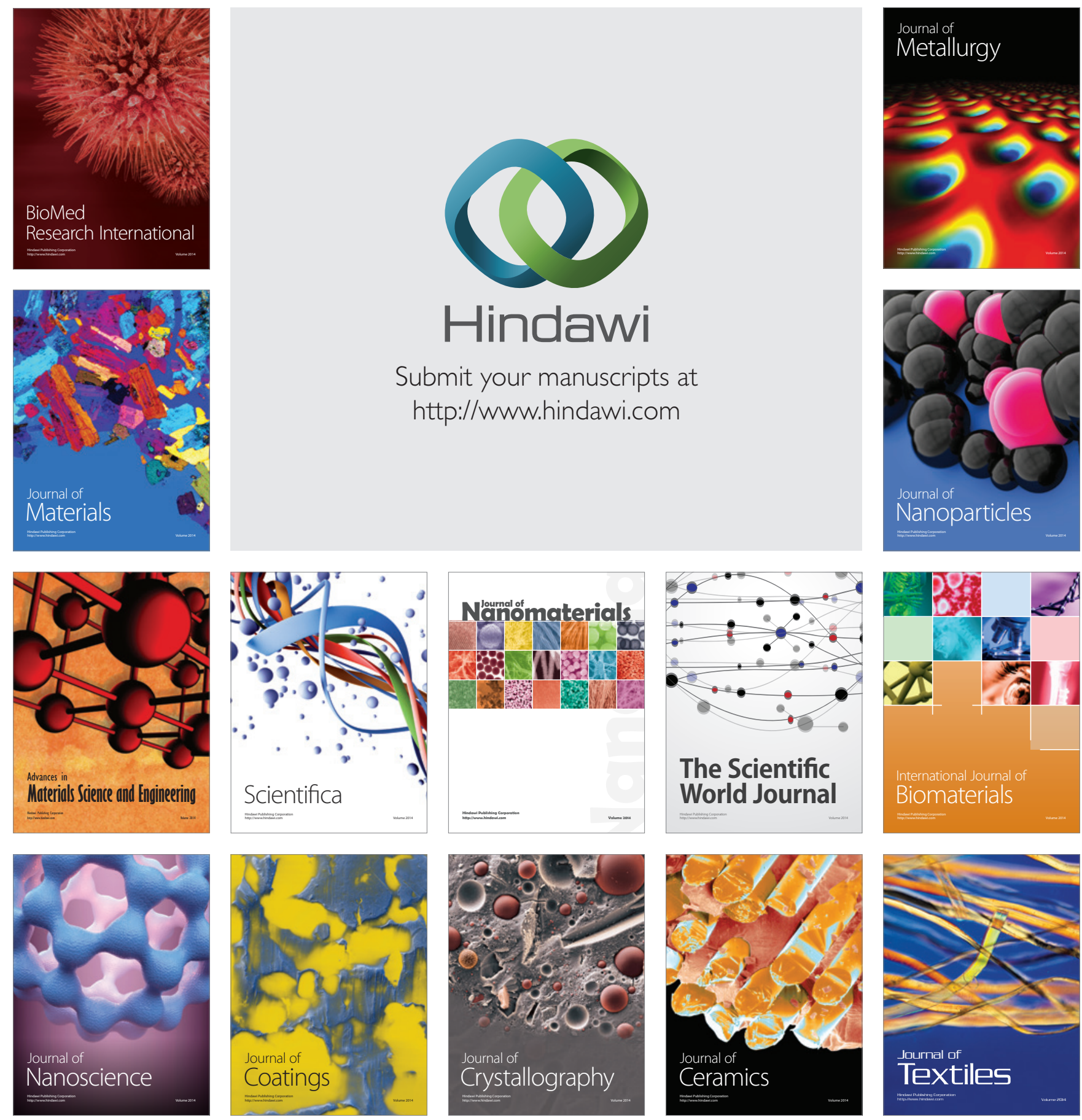